\title{
Possible Uses of Counterfactual Thought Experiments IN HISTORY
}

\author{
Alexander MaAR
}

\begin{abstract}
Counterfactual thought experiments in history have become increasingly popular in the last two decades, and a new and controversial branch of history has originated from their use: counterfactual history, also known as virtual history. Despite its popularity amongst the general public, most academic historians consider historical counterfactuals as having little epistemic value. This paper investigates three alleged uses of counterfactual thinking in historical explanations: (1) the claim that counterfactual thinking gives historians useful insights; (2) that it is a useful tool to evaluate an event's causal significance; (3) that it shows much of history to be essentially 'chaotic'. I argue that only (2) convincingly justifies the use of counterfactual thought experiments in history, as it allows historians to illustrate how they perceive events' degrees of sensitivity to changes to their causal history, being an important part of providing a causal explanation.
\end{abstract}

Keywords: Counterfactual; thought experiments; counterfactual history.

\section{Introduction: dealing with historical 'what ifs'}

Considerations about counterfactual scenarios in history, or attempts to answer to 'what might have happened had something in the past been different', are not very popular amongst many academic historians. However, for some reason such alternative $^{1}$ scenarios and their hypothetical differences to actual history have fascinated science-fiction writers for decades, and more recently 'virtual history' emerges as a more serious approach to the topic, somewhat between academic history and popular fiction. Defendants of virtual history normally claim that considering alternative outcomes is part of any historian's work, and in some cases helps illustrate how historians weight the causal importance of historical antecedents. Whether counterfactual considerations in history give us useful information or not, is what I will briefly try to answer.

It is hard to deny that, while thinking about historical facts and how they were actually caused, we do in fact consider alternative scenarios. Such considerations are not always explicit in historical explanations, but quite often they are presumed. When we say that the bursting of the housing bubble in the United States $(A),{ }^{2}$ combined with complex and high risk financial products caused the 2008 recession $(B)$, we are in fact stating that without this bursting, the crisis would not have happened, at least not the way it did.

Principia 18(1): 87-113 (2014).

Published by NEL — Epistemology and Logic Research Group, Federal University of Santa Catarina (UFSC), Brazil. 
The previous paragraph highlights an account of causation that seems to be very common and intuitive in history: causation as counterfactual dependence. If the occurrence of $B$ depends on the occurrence of $A$, had $A$ not occurred, $B$ would not have occurred either. Therefore, causation can be defined as counterfactual dependence between two or more events, and such counterfactual statements clearly instantiate David Hume's famous 'other words': "if the first object had not been, [then] the second [would] never had existed"3 (Hume 1966, p.76). Hume, however, did not develop this idea, but his insight inspired David Lewis to define causation as counterfactual dependence, and Lewis' definition, together with his elaboration of possible worlds' semantics, is indirectly responsible for the refreshed interest in virtual history.

To define causation in terms of counterfactual dependence is a promising alternative to the regularity model of causation, and it is understandable that historians would prefer this view, as it does not require reference to historical 'covering laws'. Basically, counterfactual dependence defines a cause as a 'difference-maker', because without the cause, its effect would not have happened. "We think of a cause as something that makes a difference, and the difference it makes must be a difference from what would have happened without it. Had it been absent, its effects - some of them, at least, and usually all — would have been absent as well" (Lewis 1986b, p.160-1).

Counterfactual historians do not only define causation as counterfactual dependence (had $A$ not happened, $B$ would not have occurred either), but they want to go a step further and say: 'had $A$ not happened then $B$ would not have happened either, but $C$ would probably have occurred instead'. In other words, counterfactual historians try to give a plausible answer to the question: what would have happened had any of the antecedents been different? What would have probably happened had the South won the American Civil War? Or had Hitler died during the First World War? Or if Napoleon had won at Waterloo?

In some cases counterfactual historians try to point out from a list of possible outcomes they consider as plausible the one that seems to be most likely, or closest to the actual world. ${ }^{4}$ Sometimes they move from considering an alteration of the antecedent directly to the envisaged possible scenario without further considerations, and some other times, being more cautious, counterfactual historians list the relevant plausible outcomes that might have emerged, and then try to compare them and select one as the most probable or plausible scenario. Often, the criteria used for the comparative analysis are absent, making one wonder whether counterfactual historians have 'special intuitions' about the weighting of alternatives.

In this paper I will discuss whether counterfactual thought experiments may (or should) be used by historians. In the following sections I will comment about three possible defences of the use of counterfactual thought experiments in history, and

Principia 18(1): 87-113 (2014). 
argue that at least one of them - the argument about the weighting of causes - is sound. Also, it is a fact that historical counterfactuals have been around for centuries, but a significant number of scholars have denied their use as part of providing explanations. Why is that? Before I present some reasons to be skeptical ${ }^{5}$ about the use of historical counterfactuals I will briefly discuss some aspects of historical determinism and the idea of historical necessity and contingency.

\section{An example of how counterfactual thought experiments work}

Let us see an example of how counterfactual historians work and how counterfactual historians talk about "plausible" possible outcomes. In "New Zealand as it might have been: What if there had been no Treaty?" (2007), Giselle Byrnes tries to answer what would have happened to New Zealand had the Treaty of Waitangi ${ }^{6}$ not been signed on February 6, 1840. Byrnes identifies four possible outcomes for Hobson's hypothetical failure in gathering the Maori chiefs and persuading them to sign the treaty:

(a) Maori tribes would have remained autonomous and politically independent all over New Zealand.

(b) In the absence of a legal instrument giving to the crown the right to colonise the area, British forces would have invaded by force.

(c) Some time later, France or even the United States would have claimed control over New Zealand.

(d) British settlers would have continued to colonise areas already under British control, and Maori would have continued to rule in the other areas.

Byrnes recognises that there is a number of other possible outcomes had the treaty not been signed, but she selects the four above possible scenarios as the most relevant. She then proceeds to some comparisons.

Alternate scenario (a) is improbable: "It is totally against the run of evidence and logic to assume that New Zealand, with its rich natural resources, would have been exempt from some form of external colonisation" (Byrnes 2005). Also "there is evidence that many tribes had, well before 1840, expressed a desire for British law and order and at the same time engaged in land transactions".

Scenario (b), Byrnes says, is also unlikely, given the evidence (economic reports) showing that the crown could not financially afford invading New Zealand by force. The Maori stereotype as being 'warlike' also would have helped to dissuade the British from military engagements.

Scenario (c) is a little bit more appealing, given the fact that James Clendon was appointed American consul in 1838 in the Bay of Islands, and the French organised 
a settlement at Akaroa in 1840. However, it is still an improbable outcome, given the absence of evidence about the American or French ability and/or desire to have control over larger areas of New Zealand.

Finally, scenario (d) is selected by Byrnes as the most probable. She claims that "as early as 1837 Hobson had proposed the crown assume power over certain sites in New Zealand, in much the same way that the British had established 'trading factories' in India" (Byrnes 2007). In these areas some kind of British-Maori agreement would have been necessary, but the rest of the land would have remained under Maori control.

The evident questions here are: Are these considerations of any value when compared to 'actual history'? Do these speculations about alternative outcomes give historians useful insights when it comes to explain any particularities, or the causal importance of an historical event? Or does the use of historical counterfactuals provide evidence that history is essentially chaotic? I will dedicate the next three sections to these questions.

\section{Why historians may, or should, create counterfactual thought experiments}

I have selected three possible defences for the use of counterfactuals thought experiments by historians: the first argument will discuss if some useful information can be achieved by appealing to counterfactual histories; the third attempts to demonstrate a chaotic nature of history; but only the second offers a suitable response to the question: 'why should actual historians really consider alternative worlds?' Also, I will point out that if we agree with the second argument, it is important to draw a distinction between causation and contingency, otherwise we may get caught in an old dispute about deterministic and anti-deterministic approaches to history.

\subsection{Counterfactual thinking may give historians useful insights}

Defendants of historical counterfactuals sometimes claim that in order to proceed with such thought experiments one first has to achieve a deep and vast understanding of 'actual history'. Historians must identify the chain of causal relations that take part in a historical explanation, showing that without these the actual event they are explaining would not have occurred. It is only after cautious examination of evidence, selection of relevant data, and identification of causes, sometimes according to some causal theory, that the causal explanation acquires plausibility and legitimacy. In other words, the counterfactual historian must be a skilled historian.

The Italian historian Franco Cardini, explains the importance of the historical 'ifs' by saying that: "With the 'ifs' one can bring out the infinite possibilities of the past, 
be it in terms of choices made by individuals and groups, or in terms of accidental events, one can capture the infinite variability of the processes that determine human, institutional and other structures' activities, and that also determine their outcomes"7 (Cardini 2005).

Cardini, and also others before him, suggests that there is a relevant connection between actual and counterfactual history, and that by identifying causes for a historical event, we automatically deal with the question, 'why have things occurred one way rather than another?' It seems that in order to have a complete explanation historians need to find evidence not only to explain the causal chain that actually happened, but also to explain what has prevented other possible scenarios from occurring.

That actual history provides the elements for imagining alternative scenarios is evident, but the main question here is, what does actual history have to gain from counterfactual scenarios?

A possible claim defending the use of counterfactual thought experiments would say that 'what if' questions sometimes give historians useful insights. Considerations of possible worlds could alert the historian to the fact that he has to look for evidence to confirm or deny the plausibility of the alternative scenarios. What makes the historian think that one outcome was more likely than another? What criteria does the historian use? Are the criteria somehow supported by real evidence? If so, then actual causes explaining why something has not happened could lie hidden in unexplored areas.

In one of her 'alternative outcomes' Byrnes suggests that the possibility of a French occupation of New Zealand might have caused England to sign a treaty with the Maori tribes. A French invasion is a plausible outcome only if some evidence for that can be identified and if that is the case, then at least two possible causal connections have been established - that the signature of the treaty prevented such an invasion from occurring, and that the real menace of an invasion is a cause for the signature of the treaty.

To what extent would it be acceptable to say that counterfactual scenarios are a methodological extension of historical explanations, explaining how and why it has not happened otherwise?

It seems that some causal chains are in fact not evident, and sometimes thinking about alternative scenarios leads to different sources of evidence, sources that otherwise would, perhaps, not have been taken into consideration or been granted greater importance. Byrnes mentions the absence of clear evidence that the United States or France ${ }^{8}$ wanted to colonise New Zealand. If there were any, then this would certainly be part of a causal explanation: 'the treaty of Waitangi prevented an Americanization of New Zealand', or even that its signature was 'caused' by the fear of foreign invasion.

Principia 18(1): 87-113 (2014). 
The previous case is a very simple example of the sort of questions counterfactual historians ask, and how they think these thought experiments can be a valuable tool for actual history. We could of course make the argument more sophisticated. We might want to say, for instance, that the availability of evidence of American intentions of colonizing New Zealand cannot be regarded as causes for the signing of the Treaty unless we can also prove that the British government was aware of such intentions and truly feared this scenario. In other words, it is important to assess that contemporaries have actually considered this possibility. Byrnes has to prove that a reason for Captain Hobson ${ }^{9}$ to insist on the Treaty was his intention to prevent such foreign interests to materialize. In this case, the historical agent's awareness of the plausibility of this possible world in which New Zealand becomes an American colony causally explains his action - something we might want to call Hobson's 'intentional cause'.

Investigating an agent's intentions and so explaining their actions is an important part of what actual historians do, and counterfactual thought experiments might help illuminate what the agent was aware of by pointing out possibilities, or so they claim. There is an implicit element of reenactment ${ }^{10}$ here.

So, the claim now is that counterfactual history is not just some sort of entertainment, but "a valid tool of the historian (because) by considering plausible alternative events historians are forced to analyse historical situations without the benefit of hindsight and a knowledge of what would follow (...) they must consider events as did the historical players". (Gini-Newman 2003, p.6-7).

However, I believe reenactment to be different from a counterfactual thought experiment. The empathetic exercise of trying to penetrate the mind of historical players offers insights about the possible courses of action such players might have considered, and according to what we know about their intentions we can make sense of their actions. In other words, based on what we know about the agents (by means of evidence) and their historical circumstances, we comprehend why they decided to act as they did - we understand their actions by identifying primary reasons, or the strongest set 'belief and desire'. A counterfactual thought experiment is different, it is an attempt to answer how the agents would have acted had any alteration to historical circumstances been introduced; or even how the causal chain starting from a given action would have been like ${ }^{11}$ had an agent acted otherwise claims that are much more audacious.

It is true that in some situations counterfactual thinking may give historians useful insights, becoming a valuable tool. However, it is not an indispensable tool, or at least, it is not clear how counterfactual thought experiments can provide historians any information they could not have discovered by other means. There is value in saying that by imagining alternative outcomes some actual causal chains might become more evident, but this claim alone might not sufficiently justify the use of such 
thought experiments as a necessary tool for historians.

One can say that in order to classify possible scenarios (or worlds) as more or less likely, counterfactual historians appeal to what we already know about a certain historical event: what caused it and how it happened, with nothing else being added to our knowledge. Also, good and solid explanations of how some set of antecedents determines (or influences) a certain outcome may satisfactorily explain why things did not happen otherwise.

It is also arguable whether such thought experiments are always employed to offer new insights, especially because most publications in counterfactual history occur in well-known and studied scenarios: the American Civil War, The First and Second World Wars, the fall of the Soviet Union, etc.

I suspect that counterfactual thought experiments are a useful but not indispensable tool for history, as actual historians do not necessarily need such experiments to make sense of their explanations; but they can be quite useful when it comes to one aspect of actual history: the weighting of causes, as we shall see next.

\subsection{Counterfactual thinking helps with the weighting of causal antecedents' significance}

What I believe to be the most solid answer to the question of the utility of counterfactual thought experiments with respect to actual history has to do with the weighting of causes - and this is undeniably an activity performed by actual historians. According to the type of explanation different causes will have, or better, will be characterised and described as having different degrees of importance. Counterfactual thought experiments can help actual historians to highlight their preferences and point out what causes are more predominant or fundamental.

That historians care about the weighting of causes is easily noticeable, irrespective of their philosophical positions. Defenders of the regularity theory, for example, E. H. Carr, would regard as more important those causes in accordance with some 'general historical trend'. Others, for example, I. Berlin, would argue about the causal importance of accidental detail in history, and defend the view that many historical events are the result of random, non-deterministic processes. Teleological theories of historical explanation only consider as proper historical causes the general trends, or patterns that underlie and govern the course of history. Historicism minimises or even sublimates the causal importance of the individual, and highlights historical "inevitability". In all these cases the weighting of causes seems to be quite fundamental as part of an explanation.

Berlin is a good example of a critic of so-called deterministic positions in history. He believed that determinism entails the denial of free-will, and for this reason it should be rejected. However, for the Scottish historian Niall Ferguson, editor of the

Principia 18(1): 87-113 (2014). 
popular book Virtual History (1999), historical determinism has other meanings, as it may include Marxism, for instance. In general terms, a deterministic position in history is often characterized as a defence of the existence of laws/trends/patterns of historical development, or even the existence of some general plan or impersonal forces pushing mankind towards some end (Hegelianism, for example). One must conclude that determinism may have different meanings for historians, and the use of this notion can be obscure or rather vague.

Also not always clear is what is meant by inevitability. In the case of Berlin, historical inevitability refers to the idea that everything that occurs in history does so because it must, ${ }^{12}$ and history's course could, in principle, be understood and described by laws of historical development. If we accept the claim that historical events 'inevitably' occur, then it does not seem very relevant to think in terms of 'had things been different...', as things cannot happen differently. This also explains why counterfactual historians are also not friendly towards historical inevitability.

I think of inevitability in a different way. If I say that $E$ is deterministically caused by $C$, if $C$ were to occur then $E$ would, in the absence of intervening events, inevitably occur. In other words, if nothing cuts the causal chain from $C$ to $E, E$ is the inevitable, or uniquely possible outcome. Or, I might prefer to weaken the claim of inevitability and talk about probabilities, so if $C$ were to occur then $E$ would occur with close to 1 probability. Such claims are certainly different from saying that all events happens as they must.

Berlin strongly opposed historical inevitability, and highlighted the importance of historical accidents. Berlin believed that some important historical causes cannot be characterized as the result of laws of historical development (approaches that clearly instantiate a scenario of necessity), but were the result of an accident. Historical accidents with important causal consequents would supposedly help illustrate Berlin's position that there are no general trends or patterns in history.

However, I believe accidentality — which I would simply define as an event no one could have predicted - is certainly not the claim that accidents have no immediate causes, and as such these are perfectly compatible with determinism. It would also be fairly easy for anyone who endorses the view that there are patterns of historical developments, to accommodate such accidents as minor ruptures to historical trends, or to come up with a theory explaining how historical players tend to react to accidentality as such. Once more, it is not clear how historical accidentality would help Berlin in his crusade against what he calls historical determinism.

Good examples of historical accidentality are: Gibbon's claim that had the Turkish sultan Bayezid I not suffered from gout, he could have successfully conquered most of Central Europe; or Winston Churchill's belief that had King Alexander of Greece not died of a monkey bite, the Greco-Turkish War could have been avoided. ${ }^{13}$ Berlins' approach is normally favoured by counterfactual historians, as it is relatively 
easy to imagine alternative possible worlds in such examples. Or, in other words, such events could have been easily prevented had anything in their causal history been different.

Offering an anti-counterfactual perspective, E. H. Carr (1962) dismissed such thought experiments by saying that accidental detail cannot provide a suitable causal explanation, being no more than amusing entertainment for idle minds, or a "parlour game". ${ }^{14}$ According to Carr, the counterfactual claim 'if Cleopatra's nose had been longer Mark Anthony would not have fallen in love for her and would not have lost his life' is of little value as a historical explanation as we cannot assess its truth.

What the contrast between Carr and counterfactual historians shows is that enthusiasts of accidentality in history are usually sympathetic towards the use or consideration of counterfactual thought experiments because they highlight anti-determinist positions such as the causal importance of free (indeterminate) action - or so they claim. On the other side, defendants of law-like or teleological explanations usually dismiss counterfactual thinking as being of little or no epistemic value. There is something odd about the first claim, and Ondrej Sládek has pointed it out well:

On one hand, counterfactual thinking provides arguments against historical determinism, reinstating the role of accident and non-obligatory causation, while many alternative histories assume that a single changed circumstance may affect the whole subsequent course of history. This is, naturally, a determinism not unlike the one criticised by counterfactual historians themselves. (Sládek, 2011)

Before proceeding any further it is important to underline that an important part of the dispute between Berlin and Carr could be made clearer with an important distinction in mind: that causation differs from necessity. Often, causation and necessity, and also randomness and contingency, are wrongly taken as interchangeable terms, a conflation that creates important confusions.

Instead of talking about determinism, accidentality, inevitability and other obscure notions, historians would greatly benefit from Yemima Ben-Menahem's notions of contingency and necessity. In her article "Historical Contingency" (1997) she provides a solution that cuts across Carr's and Berlin's positions while preserving the idea that all historical events are caused.

\subsubsection{Ben-Menahem's definition of historical contingency}

According to Ben-Menahem, contingency and necessity are commonly found in historical explanations. It is not rare to identify claims of the type: 'our defeat in the battlefield, given the numerical superiority of the enemy, his superior tactical position and the weather conditions favouring their position, was the inevitable (necessary) outcome'. Such an explanation has often a pragmatic purpose, such as explaining why 
a certain general should not be blamed for the defeat. On the other hand, historians may highlight the importance of some individual, describing his achievements as important antecedents for a series of events that would not have happened if it was not for one's action. In this case a certain historical event is not the necessary outcome of some antecedents, but it is contingent to an individual's actions, or perhaps to a single isolated event.

An important note has to be made at this point. This use of the terms contingency and necessity is very different from the philosophical context from where they were taken. In terms of possible worlds, for instance, a proposition A is a necessary truth if it is true in all possible worlds, and is contingent if in at least one of these worlds it is true and in another it is false. Under this perspective it is somewhat obvious to say that a proposition A is contingent, as it clearly can be false in at least one possible world. This is not what is meant by historians when they qualify some event as historically contingent or necessary.

Ben-Menahem's suggestion is that instead of criticising historians for promoting a careless use of language, it would be more constructive to redefine these notions, capturing their meaning in historical discourses. According to her, necessity and contingency, in the case of history, refer to an event's degree of sensitivity to initial conditions.

Necessity: A sequence of historical events is necessary means that a certain type of effect is a consequence of a set of different causal chains. Had one causal antecedent been absent, the same type of outcome would still occur. In other words, different types of causes lead to similar effects. As a result it can be said that the outcome has low sensitivity to the initial causal conditions.

Contingency: A sequence of historical events is contingent means that similar causes lead to different types of effects, typically showing that the type of event in question is highly sensitive to changes in the set of antecedents that give rise to it.

In extreme cases, necessity means that a given event-type is the certain and inevitable effect of some initial conditions. For instance, all possible courses for life will inevitably lead to death. In contrast, a type of effect is extremely contingent when it is highly sensitive to changes to the initial conditions because there is only one (or few) causal chain that could lead to it.

It follows from this that necessity and contingency are not absolute notions, but they come in degrees. In a stable system of causes and effects, small changes make little (or no) difference for the occurrence of the final event $E$, while in unstable systems small changes to the initial conditions do make a difference. Scenarios of necessity are relatively stable, while more contingent scenarios are relatively unstable.

We can give a more precise definition:

Principia 18(1): 87-113 (2014). 
a) $C$ is a necessary cause of $E={ }_{\text {defn. }}$ iff $c_{1}, c_{2}, c_{3}, \ldots, c_{n}$ is a set of different causal conditions and each of $C$ and $c_{1}, C$ and $c_{2}, C$ and $c_{3} \ldots$ leads to an event of the same type of $E$. That is, the occurrence of $C$ in any of the conditions $c_{1}, \ldots, c_{n}$ is stable in the sense that they all lead to the same type of $E$.

b) $C$ is a contingent cause of $E={ }_{\text {defn. }}$ iff $c_{1}, c_{2}, c_{3}, \ldots, c_{n}$ is a set of similar causal conditions and $C$ and $c_{1}$ lead to $E_{1}, C$ and $c_{2}$ lead to $E_{2}, C$ and $c_{3}$ lead to $E_{3}$, $\ldots$ and all the $E$ s are sufficiently dissimilar events. That is, the occurrence of $C$ in any of the conditions $c_{1}, \ldots, c_{n}$ is instable in the sense that they all lead to different types of $E$.

In the case of historical discourse, however, extreme situations of necessity or contingency are rare, and historians are entitled to speak of degrees up to the least contingent viz. the necessary. Simplifying the definition, it is enough to say that as contingency and necessity are opposites of each other: contingency increases in direct proportion to sensitivity to initial conditions, and necessity increases in reverse proportion to them. This approach developed by Ben-Menahem avoids the conflation of causation and necessity: all events have a causal history, but types of events may be described as highly contingent or not. As a result "we can get a high degree of contingency in a perfectly deterministic process, so causality does not entail necessity" (Ben-Menahem 1997, p.103). Causation and necessity are both relevant to historical explanations, but we cannot reduce one to the other, as Ben-Menahem argues.

Adopting this distinction we can see that Carr and Berlin do not have to disagree on historical causation - the belief that all historical events are caused - , but they certainly are on different sides regarding necessity and contingency. Carr privileges scenarios of higher levels of necessity as suitable for historical explanations; while Berlin suggests much of history to be highly contingent, being therefore important to study historical 'accidents', i.e., events that could easily have been avoided, as they are highly sensitive to changes to the initial conditions. Much of the dispute between Carr and Berlin can be regarded as a confusion of categories (causation and necessity), as pointed out by Ben-Menahem.

Contingency certainly requires causation. Pascal's famous remark about Mark Anthony's fascination by Cleopatra's nose is certainly an event with a causal history. It could also be described as highly contingent: had the nose been any longer he would not have fallen in love with the Egyptian queen. Certainly a description of the fall of the Roman Republic based on a single causal chain (Mark Anthony's love for Cleopatra) would be very naive, and no historian would seriously attempt such an explanation. There are multiple causal chains leading to an effect of the type 'the fall of the Roman Republic'. However, a description of Mark Anthony's choices as a political leader could be characterised as very sensitive (contingent) to changes of some antecedents, like his passion for Cleopatra. 
Contingency may be an important part of an historical explanation, depending on the extent and the nature of the explanandum. Isaiah Berlin's historical 'accidents' can be described as highly contingent events, but they do have a cause or causes. Highlighting accidental detail in history may, or may not be important - how much attention should be given to it can only be answered case by case. Contingency, however, offers no support for genuine randomness in history, or to the claim that there is no such thing as a historical cause that determines the occurrence of some effect.

Defending the idea that history is a sequence of genuinely random events seems to imply that there is no causation in history. An obvious objection to this view is that historical explanations that do not refer to causes are meaningless, becoming simple narratives of genuine chaotic nature, and very few historians would hold such a belief. At the same time, contemporary historians are normally against teleological or law-like explanations mostly because they seem to deny the causal importance of individuals and reflect an 'aura' of determinism - even though it is not clear what is meant by it.

As history is a very complex chain of causal relations, defendants of the importance of historical contingency claim that even if in some situations we can identify some apparent 'trend' or pattern, law-like explanations cannot be satisfactorily established. They also claim that in most historical scenarios chains of events can dramatically change if we introduce any alteration to a single antecedent. Ben-Menahem's distinctions offer a solution for those who believe that an important part of history is very contingent, but agree that all explanations must be causal — highly contingent events need not be the result of random processes, they appear to be chaotic, but may well be the product of deterministic systems.

Another advantage of separating necessity and causation has to do with the problem of free will and human agency 'making a difference' to the world. In BenMenahem's perspective determinists or libertarians will both be interested whether the result of some action is part of a contingent or necessary causal chain. It does not really matter, for the sake of explanatory description, if an action was truly free or predetermined, because even the latter can be seen as 'making a difference' if part of a highly contingent causal chain, and less so if part of a scenario described as necessary - usually cases in which some type of event is determined (or over-determined) by multiple causal chains.

Ben-Menahem believes that by carefully distinguishing between causation and necessity historians need not adopt opposite positions regarding what is the most fundamental historical category: necessity (as exemplified by historicism - Hegel and Marx) or contingency (as exemplified by Berlin's anti-historicism). Intermediate positions can adequately be defended, and historical explanations remain causal even if they appear chaotic.

Principia 18(1): 87-113 (2014). 
Depending on the description of the chain of causal relations an explanation is characterized as tending towards differing degrees of necessity or contingency. As Sládek has adequately explained: "the logic of counterfactual thinking, which borders on the logic of fiction on the one hand and with the logic of history on the other, is a logic based on [preserving] the causality of historical development while relativizing hierarchies of historical events." (Sládek 2011)

\subsubsection{Exemplifying relative contingency}

The contrast between contingency and necessity illustrates the idea that counterfactual thought experiments entail counterfactual dependence of a final event $e$ on some cause $c$, and this serves as basis for a discussion that is quite independent from a conceptual analysis of causation: the description of a historical causal scenario of relative contingency. Two possibilities arise. (1) An event of type $E$ would have occurred even if such and such of its antecedents $\left(c_{1}, c_{2}, c_{3}\right)$ had not occurred or had been different. In this case $e$ is understood as relatively less contingent and more necessary. (2) An event of type $E$ would not have occurred had any of its causal antecedents been absent or slightly different. In this case $e$ is understood as relatively more contingent and less necessary ${ }^{15}$ in that context. The occurrence of the actual event $e$ depends solely on the occurrence of $c$, but the occurrence or not of an event of the type of $E$, after considerations about alterations to $\left(c_{1}, c_{2}, c_{3}\right)$ depends on how the explanandum is characterized in terms of relative contingency, if we take Ben-Menahem's definition.

Returning to my initial question, is virtual history of any value compared to 'actual' history? The answer seems to depend on our acceptance of the view that such speculations help us to decide about the comparative weight of historical causal antecedents. If this can be demonstrated, then the answer is yes. The point is not about writing 'history that never happened', but focusing on plausible immediate changes that would be caused by alterations to known historical antecedents, under a certain description. For instance, deciding whether a certain event is of a type expected to occur as the result of long term social or economic forces, or the contingent outcome (event-token) of, for instance, free human agency.

Let us illustrate how comparing relative levels of contingency work using two contrastive and simplified examples.

In 'Camelot Continued' Diane Kunz investigates whether the United States would have Americanized the war in Vietnam had John Kennedy not been killed in Dallas and then gone on to win the 1964 election in the place of Lyndon Johnson. Her conclusion is that there is no evidence suggesting that things would have evolved much differently from what actually happened. She suggests that just before his death in 1963, Kennedy was considering to withdraw part of the troops from Vietnam, based

Principia 18(1): 87-113 (2014). 
on advisors' reports that the current level of aid to the South Vietnamese was sufficient for a victory. A few months later the same advisors realized the magnitude of their problems and Johnson had to act decisively. According to Kunz, Johnson was more concerned with domestic affairs than external policy; therefore his disengagement from the war was more likely than Kennedy's. She concluded that had Kennedy won the election, active American engagement in the war would not have been substantially changed, and some very similar type of event was likely to occur.

Kunz's case study illustrates what I believe to be a good understanding of the way historical counterfactuals might be useful; when historians explain an event based on what they consider to be a relevant part or its causal history, they automatically characterize the event as more necessary, or more contingent. This 'contingency' of the events might help us, for example, to assess the Vietnam War as a more necessary event, since an alteration to its causal history (having Kennedy as US president in the place of Johnson) would not have made much of a difference, or so Kunz believes. In this case Johnson's level of historical responsibility for the Americanization of the war decreases accordingly, or the causal importance of Johnson's leadership becomes characterized as less important than the wider general context of world diplomacy during the Cold War. This is an important consideration because it affects the way we understand the conflict.

An opposite example is provided by Mark Amond in '1989 without Gorbachev' in which he investigates the causal importance of the General Secretary Mikhail Gorbachev's reform acts to the fall of the Soviet Union. Amond reviewed some political analysts' statements from the 1980's about the probable longevity of the Soviet Union, and concluded that they were probably right in saying that the Soviet Union was not coming to an end anytime soon if it was not for the fact that their new leader was an honest man. Gorbachev did not know how irresilient the Soviet system was until he tried to conduct some reforms which ended with the fall of communism. Amond believes, and provides some evidence for the claim, that a more 'cynical' leader would have prolonged the life of the Soviet Union, and would have dealt with the challenges (high oil prices, outdated technology, etc.) using other methods. If we grant Amond's example as plausible, then the causal importance of Gorbachev's actions is high. In order to explain the fall of the Soviet Union a historian could not neglect undertaking a deep analysis of Gorbachev's views and intentions. In this case, the fall of the Soviet Union is interpreted as very contingent because of its causal dependence on Gorbachev's actions - had Gorbachev acted differently, a very different type of event would probably have occurred, such as the Soviet Union surviving longer.

These contrastive examples are of course simplifications, and one could easily argue that there are an infinite number of variables involved in both cases, and for many of these we have no evidence. It can be argued that every historical event is

Principia 18(1): 87-113 (2014). 
hugely complex, and it is an illusion to think that we can actually assess one outcome to be more likely than others. All attempts of prediction in history failed exactly because of its very complex nature, because all historical events are connected in incalculably vast chains of causal relations. Ferguson (1999) and others have suggested that scenarios of relative necessity are very hard to defend, as history appears to be chaotic (or extremely contingent).

But if so, what makes Ferguson think that counterfactual scenarios give us any useful information? If history is to be depicted as essentially chaos, how can we compare possible worlds and say which one of them is closer to the actual world? What is a plausible alternative if history is essentially chaotic?

Indeed history has a complex nature, but our understanding of historical phenomena, our individuation of events and explanations of events' occurrences are not chaotic. In order to make sense of their causal explanations historians are forced to select what apparently are relevant causal antecedents and discard some others, describing a world in which the selected relevant factors appear to be sufficient to explain the occurrence of a certain final event. In a certain way, the hugely complex nature of history has to be ignored, as the actual chains of causal relations cannot be perfectly and completely understood. Historical causation differs from historical causal explanation, as the latter will always be a sketch, an imperfect attempt to portray reality.

\subsection{To show that history is essentially chaotic}

As in the case of determinism and inevitability, it is not clear what historical chaos means. Apparently, when chaos theory is applied to history, it means that historical events are understood as forming very complex chains, and the causal relations are highly sensitive to changes to the initial condition. So, I believe it would be correct to say that historical chaos means something very similar to high levels of historical contingency.

Niall Ferguson defends the use of counterfactual or alternative scenarios as some sort of 'proof' of his belief that history seems to be chaotic. Consider the case of events caused by natural events. The events historians "try to infer from these sources were originally stochastic - in other words, apparently chaotic — because the behaviour of the material world is governed by non-linear as well as linear equations" (Ferguson 1999, p.89).

Ferguson's perspective is that much of history is apparently chaotic; his position is anti-historicist and anti-teleological, views that, according to him, express some sort of 'determinism'. ${ }^{16} \mathrm{He}$ argues that no historical event is apparently 'inevitable'. He claims that it is always the case that any alteration to a historical antecedent could provoke enormous differences to the way the future is going to be, thus making

Principia 18(1): 87-113 (2014). 
prediction impossible. By considering alterations to historical events and creating plausible narratives of possible worlds, Ferguson intends to demonstrate the absence of known laws of historical development, and to defend the application of chaos theory to history:

[...] all that chaos theory says is that certain realms of the world are governed by equations so complex, non-linear equations, that it's extremely difficult $[\ldots]$ to predict patterns [...] there are causal sequences, but they are so complex that the outcomes appear to be random and therefore are extremely hard to predict [...] chaos theory works very well for history because it says the world is actually governed by causal relationships, causation is real, but is highly complex. And therefore to imagine that one can predict it or reduce it to a few linear laws is hopeless and fanciful. (Ferguson, cited by Gini-Newman 2003, p.6)

In short, what Ferguson defends is that history appears to be chaotic given the complexity of the real causal relations. He also maintains that in some situations this chaotic aspect becomes more evident, for instance, when elements like the weather conditions act as causes for a certain historical event.

Another attempt to defend the applications of chaos theory to history has previously been made by George A. Reisch in 'Chaos, History and Narrative'. According to Reisch, chaotic behaviour is determinate and law governed, and chaos should not mean that events may occur randomly or with no apparent cause. Historical events are underpinned by causal physical mechanisms. Similarly to Ferguson, Reisch believes that most historical events are very sensitive to variations to initial conditions; therefore even minimal differences to the causal history of an event may cause great variations to the final effects.

Amongst the examples mentioned by Reisch one deserves our attention: "what the world might look like today if a person only slightly more combative than Khrushchev had been at the Soviet helm during the Cuban missile crisis - certainly very different if nuclear war had ensued" (Reisch 1991, p.6).

It seems correct to say that human actions, considered quite independently from a larger social, cultural environment, appeal to the notion of chaotic behaviour even slight differences to an agent's 'mood' could potentially be followed by different actions and consequently different types of outcomes. In that sense 'Cleopatra's nose' could be a decisive causal factor, leading to a variety of possible outcomes. But history is not just biographies, and when historians refer to races, nations, economic systems, financial corporations, cultural and religious changes, they seem to presuppose that larger processes are not chaotic. Reisch suggests that historians do not consider them chaotic because we lack the intimacy with their causes and effects.

Reisch recognizes that in the case of Khrushchev's actions during the missile crisis it is not so easy to relate his temperament to the fact that World War III had 
not occurred. As he says, it is possible that Khrushchev anticipated for years what he would do in the case of a USA ultimatum to remove the missiles. Or even that his actions were just "expressions of larger and more stable social and economic forces whose particular strength and direction were insensitive to his idiosyncrasies" (Reisch 1991, p.8). If others were in the shoes of Kennedy, Khrushchev or McNamara, some very similar historical outcome would (likely) have occurred.

However, Reisch believes that despite all social and economic forces, it is always the case that the most trivial factor could generate huge alterations within the historical structure a player is confined to. He believes that historical structuralism, for instance, ignores l'histoire événementielle(a history of events) because it confounds constraints with determination. Therefore geographical factors, for instance, limit but do not determine historical possibilities for a certain group of people, but within these "envelopes" of possibilities, unpredictable and chaotic things may happen.

Reisch and Ferguson have been criticised for the exaggerated and universal emphasis on the chaotic, non-linear behaviour of historical processes. John Reilly asserts: “(...) changes from generation to generation in modern times do not appear to me to be altogether chaotic. There are conspicuous linearities in the history of the past few centuries, whether we are talking about population growth, economic output or even longevity". (Reilly 2000). Reilly suggests that such trends, even if they do not go forever, "seem to be impervious to minor accidents. It is probably also true that certain cultural trends over the same period have a trajectory with a similar, intrinsic durability. If these things are true, then counterfactuals must respect a 'main sequence' that runs through modernity". Reilly finally concludes his critique by stating: "(...) there have been periods like modernity in other times and places, and even (...) history as a whole has a loosely defined trajectory". (Reilly, ibid.)

What I believe causes some confusion, and motivates criticisms such as Reilly's ones, are some of Ferguson's remarks that virtual histories are not compatible with what he calls 'historical determinism', suggesting in his "Foreword" to Virtual History that history is chaos without a direction. I cannot see why counterfactual plausible scenarios would be incompatible with such deterministic approaches - as previously mentioned, the idea that the present counterfactually depends on the past, that 'had anything different happened in the past, the present would have been different' seems to be a deterministic claim.

I certainly agree with Ferguson that historicism is unlikely to be a true theory, or that teleological explanations have no or little epistemological value. But I cannot see why such thought experiments would be 'incompatible' with deterministic ${ }^{17}$ approaches to history, or how they demonstrate them to be false. Ferguson's counterfactual thought experiments normally suggest that changes to antecedents in history will likely be followed by major transformations to the present. However, I might, for instance, create a thought experiment that suggests the opposite, by describing 
alternative scenarios in which alterations to the antecedents are always followed by the same type of final event, giving enormous weight for any evidence that supports this idea, while minimizing others. But, will it prove history to be in reality deterministic? Or will it solely demonstrate that my explanandum has been described in a way to portray a high level of necessity, irrespective of what the real nature (chaotic or not) of history is?

\section{Final remarks: historical counterfactuals and determinism}

In the previous pages I have attempted to analyse three possible uses of counterfactual thought experiments in history: (1) the claim that counterfactual thinking gives historians useful insights; (2) that it is a useful tool to evaluate an event's causal significance; and (3) that it shows much of history to be essentially 'chaotic'. I have also presented the notion of causation as counterfactual dependence, as a better definition of an historical cause.

I have argued that while (1) has some epistemic value, it still lacks a proper justification. One can easily argue against this view by saying that counterfactual thinking does not provide any new evidential information about the actual world - a counterfactual scenario is rather a product of our perspective of the world, of the causal links we have already perceived, and how these are described. A proper justification of this claim would have to show how counterfactual thinking is part of the method of history, which means that it can work as a guide for the identification of causal relations, telling us where to look for evidences. While it seems intuitive to think so, there seems to be no evidence that such causal claims could not have been properly identified by means other than counterfactual thinking.

I strongly believe that claim (2) has epistemic value, as it has indeed the capacity of providing a tool for historians. It is a tool for the evaluation of the causal importance of the initial conditions, or causal antecedents, from which they infer the causal history of a given event - the weighting of causes. Counterfactual thinking accords with our intuitions that we attribute causal responsibility to agent causation, for instance, exactly because we ponder how things could have evolved had the agent decided or acted differently. Moreover, historical events, which are normally understood as being complex and intricate, are the result of many different causal chains and therefore it is a natural attitude of historians to imagine how different things would have been had one of the antecedents been absent or different.

Cases of overdetermination, for example, rapidly lead to an account of the historical event that, according to Ben-Menahem's definition of historical contingency/necessity, portrays a scenario of a high level of necessity. In this case, individual actions are understood as having a minor causal importance, as alterations to these are un-

Principia 18(1): 87-113 (2014). 
likely to be followed by a different type of consequent. We can express this notion in terms of possible worlds: any world $(w)$ where a single alteration is followed by the same type of consequent, is closer to the actual world ( $w @$ ), than any possible world in which the alteration is followed by a different kind of consequent.

As for events described as highly contingent, the causal importance of any antecedent event is high, as any alteration to it will most likely be followed by a different type of consequent. Or in terms of possible worlds: any world $w$ where a single alteration is followed by the same type of consequent, is more distant to the actual world w@, than any possible world in which the alteration is followed by a different kind of consequent.

With regards to (3), Niall Ferguson mantains that history should be understood as analogous to chaos theory - historical events are so intricately complex that it is always the case that any minute alteration to the initial condition might result in a vastly different type of consequent. For him, much of history would appear as a chaotic narrative. But because chaotic systems can be deterministic, such an analogy can offer no solution to the plausibility of the doctrine of historical determinism. Also, because some events are overdetermined, leading to higher levels of historical necessity, it is clear that, in some situations, conspicuous non-chaotic linearities are perceived, which seems to reject the claim that all, or most, of history is apparently chaotic. While thought provoking, it is still unclear how chaostory ${ }^{18}$ (Fergusson 1999) might contribute to an analytic approach to the philosophy of history. Such unclarity can only be dissipated with a proper demarcation of which aspects of history are chaotic, and which are not. If such a line can be drawn, then chaostory becomes a plausible theory.

I've also drawn attention to an underlying issue known as historical determinism - a notion that has been used as a reference to a different range of theories, from scientific models of explanation to Hegelianism. Historical determinism is normally rejected by defendants of counterfactual thought experiments in history.

Roughly speaking, determinism can be defined as the view that the state of the world at time $\left(t_{1}\right)$, according to a general hypothesis or theory $(T)$, uniquely fixes the state of the world at $t_{2}$ for some empirical magnitude $(m)$. In other words, the final state of the world could not have been different with respect to $m$, unless something in the initial conditions, or in $T$, had also been different. If history is indeterministic, then the set of initial conditions under $T$ does not uniquely fix the state of the world at $t_{2}$. Universal determinism, also known as Laplacian determinism, states that $T$ uniquely fixes the state of the world at any time $\left(t^{\prime}\right)$, with respects to all magnitudes ${ }^{19}\left(\mathrm{~m}^{\prime}\right)$. One way for history to be Laplacian (futuristically) deterministic is for there to be a Grand Theory $\left(T_{G}\right)$ that determines everything. ${ }^{20}$

Regardless of determinism being a true theory or not, and irrespective of the existence or not of laws of historical development, for the sake of providing a causal 
explanation of the state of the world at $t_{2}$, the set of initial condition at $t_{1}$ is understood as the cause (or probable cause) for the state of the world at $t_{2}$. Therefore, providing a causal explanation is solely to provide information of the causal history of an event, ${ }^{21}$ and does not imply demonstrating that $E$ is the uniquely possible state of the world at $t_{2}$, with respect to some $m$, given the antecedents in conjunction with $T$, as a deterministic system would entail.

Given the fact that determinism is not a verified theory - rather the opposite, there is evidence which suggests that some empirical magnitudes of nature are not deterministic - I would certainly prefer to talk about probabilities: if the causal conditions of a certain effect are well-known, then I can say with close to 1 probability that (in the absence of any interfering factor) $C$ causes $E$. Or, as Lewis suggests, in an indeterministic system the occurrence of $C$ increases the probabilities of $E$ to occur, had $C$ not happened, $E$ would probably not have happened either. In a charitable use of the word, if $E$ occurs with close to 1 probability, I might say that $C$ determines the occurrence of $E$, and such a claim does not imply any reference to, say, Laplacian determinism, or any similar approach.

So, why is historical determinism a problem for counterfactual historians?

A central point for defendants of counterfactual history is to say that it makes perfect sense to inquire: 'what would have happened had something in the past been different?' or what would have happened had $x$ (agent) decided to act differently than he did?'. In the past and still today, historians sympathetic to the use of 'what if' questions, or speculations about possible alternative outcomes for key historical events, are very wary of what they consider to be 'deterministic doctrines' of history. In general, it is believed that historical explanations should not make use of 'deterministic' theories as these lead to some account of 'historical inevitability', and minimise the causal importance of historical players. Historical inevitability is a vague notion, as it can refer to (a) the belief that free human agency is an illusion; or (b) that historical events happen as they must (according to natural or supernatural laws), and that it is therefore not relevant to investigate whether things could have happened otherwise.

My point regarding this subject is that the association of 'determinism' as leading to an account of 'historical inevitability' or 'universal determinism' is not straightforward, and depending on how these two notions are defined there should be no reason to reject all deterministic theories of explanation on the basis of incompatibility with counterfactual speculations. It seems that only universal determinism (Laplace, 1951) represents an obstacle to counterfactual thinking, as it entails that all empirical magnitudes $m^{\prime}$ of nature are determined by a previous state of the world, and some Grand Theory $T_{G}$, rendering impossible to introduce alterations leading to possible alternative worlds exactly because all magnitudes are causally related and determined by $T_{G}$ at all times $t^{\prime}$. However, if we say that some magnitudes $m$ at $t_{2}$ is 
causally determined by $T$ and a previous state of the word at $t_{1}$, there is no reason to believe this assumption would clash with counterfactual thinking.

Clearly, counterfactual thought experiments cannot help us decide which theory - historical determinism or indeterminism - is true, but because either is compatible with counterfactual thinking, such thought experiments can offer historians a tool for the description of historical scenarios as portraying different degrees of historical contingency/necessity - irrespective of a truly deterministic or indeterministic nature of history. Contingency and necessity are different notions than determinism and indeterminism, and capture better the historians' weighting of causes.

Defenders of historical determinism profess that historians should try to replicate the success of the natural science by looking for patterns, laws or regularities. Indeterminists say that the laws (if any) are at best probabilistic. A third position, the anti-naturalist view, says that providing an historical explanation does not require reference to causal laws, but to providing reasons for which historical agents acted as they did - and reasons are normally understood as being non-reducible to physical properties. Whether laws of historical developments can be properly established, or not, seems to be an important problem for all these approaches.

Causation as counterfactual dependence simplifies much of these controversies, as it does not require inference to laws or regularities - at the same time it does not deny that such laws could indeed exist, or that some regularities are meaningful. Under Lewis' definition of causation (1986a), it does not matter whether the agent's reasons are the result of indeterminate, non-reducible mental processes, or the result of strict regularities of nature (or the outcome of probabilistic laws): if the agents' actions, and also his reasons for acting, are part of the causal chain leading from $C$ to $E$, then they count as causes - they become event's causal antecedents - and we are entitled to say 'had the antecedents not been, the consequents never had existed'.

I favour the view that determinism is a theory or doctrine that can only be proven false empirically, and not by means of metaphysical speculation, or thought experiments. Historical determinism (except for universal determinism), even if unlikely true, is certainly not incompatible with counterfactual history; but it is irrelevant for the construal of a causal explanation. Whether an agent's actions are the result of natural covering laws, or laws of historical development, or the result of free indeterministic will, it makes no difference whatsoever to the fact that his actions are part of a causal chain and shall be accounted for in any causal explanation; and because the agent is part of the causal chain, alterations to his actions will (or are likely to) cause alterations to the consequents.

What is of interest to historians is precisely how influential such causal antecedents are perceived to be for the occurrence of a certain outcome. This is a worry that can only be represented by means of counterfactual thought experiments, cashed out in terms of possible worlds' semantics; a notion that needs to be comple- 
mented with a definition of contingency/necessity in historical explanations. The beauty of Ben-Menahem's definition of historical contingency is that it captures precisely how the weighting of historical causes is to be performed, while leaving the problem of historical determinism undecided.

Counterfactual history's contribution towards actual history is the provision of a tool for the weighting of causes, and historians do not have to take a position on determinism in order to develop a good causal explanation. Historians might prefer to say that some effect was determined by the conditions, or prefer to be more cautious and talk about what the 'probable' outcome was, given the antecedents. In the sense of providing understanding of a historical problem of the kind 'why did $x$ occur at a time $t$ ', both approaches offer good results. Regardless of the position taken on issues to do with determinism, a good explanation is one that gives us useful information of the causal history of an event.

This brings us to the central point of this paper, to highlight the necessary connection between counterfactual history and these two notions: historical necessity and historical contingency. Where we have single or few causal relations, contingency seems to be an important feature of a historical explanation. However, where we have complex chains of events, where one final effect is understood as the result of a myriad of causes, ${ }^{22}$ historical 'necessity' seems to represent what is intended in this case the causal importance of each antecedent, when taken in isolation from the context, is reduced.

Some might say that historical descriptions with higher levels of contingency, where a single act is responsible for the occurrence of important events, create scenarios of apparent chaos. Others would suggest that scenarios regarded as highly necessary suggest the existence of an historical trend or pattern. But a decision on these matters, whether to believe in laws of historical development or not, has to do with historians' philosophical preferences, and cannot be decided based upon counterfactual thought experiments. This is why historical contingency is a better notion than indeterminism, and historical necessity a better notion than determinism if we are to explain the occurrence of a historical event.

Counterfactual thinking cannot tell us which category of history is the most fundamental one (necessity or contingency) or the theory most likely to be true (determinism or indeterminism). Ferguson, Tucker, Sládek, and others, have already suggested that the weighting of causes is the most important contribution of counterfactual history towards actual history. My intention is solely to highlight that by accepting counterfactual thinking as a tool for assessing the causal importance of historical antecedents, we consequently accept that counterfactual historians can find ways or criteria to hierarchise these alternative scenarios according to their likeness' or 'plausibility' - or organise the possible worlds according to their distance from the actual world, if we are to use proper semantics. Nevertheless, we ought to draw a 
distinction of the kind Ben-Menahem has developed, avoiding the conflation of causation and necessity while maintaining that the controversy between determinism and indeterminism remains unresolved.

In short, I defend the view that counterfactual thought experiments are an important part of the way historians create causal explanations, as they illustrate the relative importance of causal antecedents. Such experiments cannot, however, help us to decide between determinism/indeterminism, as some counterfactual historians seem to believe. Depending on how the explanandum is described, a causal explanation will resemble a certain level of 'necessity/contingency', showing how determining ${ }^{23}$ or necessary some factor was in one's understanding of what actually happened - for the sake of historical understanding this is what really matters.

Finally, I shall draw attention to the fact that the analytic approach to the philosophy of history I defend is certainly not the only possible option. But it is highly productive exactly because it helps bring clarity to an issue that has obscured the philosophy of history for centuries: whether we are or not entitled to imagine things to have happened otherwise, and what epistemic value can we attribute to such speculations. Ponderations about possible worlds do not conflict ${ }^{24}$ with any contemporary philosophical standpoint of the logic of historical developments, and offer good advice for how important the causal antecedents - taken individually — are perceived to be. To consider historical alternative possible worlds is not a necessary feature of historical thinking, but it is certainly an useful one.

\section{References}

Amond, M. 1999. 1989 without Gorbachev. In: Ferguson 1999, 392-415.

Ben-Menahem, Y. 1997. Historical Contingency. Ratio 10: 99-107.

Berlin, I. 1954. Historical Inevitability. Oxford: University Press.

Byrnes, G. 2007. New Zealand as it might have been: What if there had been no Treaty? In: The New Zealand Herald, Jan 8. Available at http://www.nzherald.co.nz/books/news/article.cfm?cid=134 \& objectid=10418071

Cardini, F. 2005. La Storia al condizionale. In: F. Cardini (Editor) Se l'Italia - Manuale di storia alternativa da Romolo a Berlusconi. Ed. Vallecchi.

- 2013. Trecentotrenta anni or sono. Available at http://www.francocardini.net. Published on 31/01/2013.

Carr, E. H. 1962. What is history? New York: Knopf.

Child, W. 1996. Causality, Interpretation and the Mind. Oxford University Press.

Climo, T. A.; Howells, P. G. A. 1975. Possible Worlds in Historical Explanation. History and Theory Vol. 15(1): 1-20.

Collingwood, R. G. 1994. The Idea of History. Oxford: Oxford University Press.

Earman, J. 1971. Laplacian Determinism. The Journal of Philosophy Vol. 68(21), Sixty-eight Annual Meeting of the American Philosophical Association Eastern Division (Nov. 4): 729-744.

Principia 18(1): 87-113 (2014). 
Elster, J. 1978. Counterfactuals and the New Economic History. In: Logic and Society Contradictions and Possible Worlds. Chichester, New York, Brisbane, Toronto: John Wiley \& Sons, p.175-232.

Ferguson, N. (ed.) 1999. Virtual history: Alternatives and Counterfactuals. New York: Basic books.

Gini-Newman, G. 2003. Counterfactual history: Good Teaching, Bad History? Journal of Ontario History and Social Science Teachers' Association. Rapport Fall.

Hawthorn, G. 1991. Plausible Worlds - Possibility and understanding in history and the social sciences. Cambridge: Cambridge University Press.

Hornsby, J. 2003. Agency and Causal Explanation. In: J. Heil, J.; A. Mele, Mental Causation, Oxford: Oxford University Press.

Hume, D. 1910. An Enquire Concerning Human Understanding. Harvard Classics Volume 37, P.F. Collier \& Son. Available at http://18th.eserver.org/hume-enquiry.html

Jackson, F. ed. 1991. Conditionals. Oxford: Oxford University Press.

King, J. C. 2007. What in the world are the ways things might have been? Philosophical Studies 133: 443-453.

Kunz, D. 1999. Camelot Continued. In: Ferguson 1999, 368-91.

Laplace, P. S. 1951. A Philosophical Essay on Probabilities. Translated into English from the original French 6th ed. by Truscott, F. W. and Emory, F. L., New York: Dover Publications.

Lewis, D. 1986a. Causation. In: Philosophical Papers vol. II, Oxford: Oxford University Press, p.159-213.

- 1986b. Events. In: Philosophical Papers vol. II, Oxford: Oxford University Press, p.241-270.

- 1986c. Counterfactual Dependence and Time's Arrow. In: Philosophical Papers vol. II, Oxford: Oxford University Press, p.32-52.

Mandelbaum, M. 1977. On Determinism. In: The Anatomy of Historical Knowledge. Baltimore: Johns Hopkins University Press.

Martin, R. 1977. Historical Explanation: Re-Enactment and Practical Inference. Ithaca and London: Cornell University Press.

Menzies, P. 2009. Counterfactual Theories of Causation. The Stanford Encyclopedia of Philosophy (Fall Edition). Available at http://plato.stanford.edu/archives/fall2009/entries/causation-counterfactual.

Reilly, J. 2000. Review of Ferguson, N. (1999): (ed.) Virtual history: Alternatives and Counterfactuals. New York: Basic books. Available at http://www.johnreilly.info/vihi.htm

Reisch, G. 1991. Chaos, History and Narrative. History and Theory Vol. 30(1): 1-20.

Sainsbury, R. M. 2001. Logical forms, an introduction to philosophical logic. Malden: Blackwell Publishers.

Sládek, O. 2011. Between History and Fiction: On the Possibilities of Alternative History. Text presented at the Colloquium Fictionality / Possibility / Reality / II. Prague, Czech Republic, April 18-21. Available at http://www.flu.cas.cz/fictionality2/sladek.pdf

Suetonius, J. 1913. The life of Julius Caesar. In: The lives of the twelve Caesars. Available at http://penelope.uchicago.edu/Thayer/E/Roman/Texts/Suetonius/12Caesars/Julius* .html

Tremewan, P. (Ed.). 1990. French Akaroa: an attempt to colonise southern New Zealand. Christchurch: University of Canterbury Press.

Principia 18(1): 87-113 (2014). 
Tucker, A. (Ed.). 2009. A Companion to the Philosophy of History and Historiography. Boston: Wiley-Blackwell.

. 1999. Historiographical Counterfactuals and Historical Contingency. History and Theory 38: 264-276.

\author{
Alexander MaAr \\ University of Auckland \\ NEW ZeALAND \\ alexander.maar@web. de
}

Resumo. Experimentos contrafactuais em história tornaram-se populares nas últimas duas décadas, dando origem a um novo e controverso ramo historiográfico: a história contrafactual, também conhecida como história virtual. Apesar da sua popularidade entre o grande público, muitos acadêmicos consideram tais experimentos como sendo de pouco valor epistêmico. Este artigo propõe-se a investigar três possíveis usos para o pensamento contrafactual na explicação em história: (1) a afirmação de que o contrafactuais proporcionam insights úteis; (2) de que se trata de uma ferramenta útil para a avaliação da importância causal de um determinado evento; (3) de que seu uso demonstra a essência caótica da história. Argumento que apenas (2) justifica de forma convincente o uso de experimentos mentais contrafactuais em história, pois estes permitem aos historiadores ilustrar como percebem o nível de sensibilidade dos eventos às alterações em seus antecedentes causais, tornando-se parte importante de uma explicação causal.

Palavras-chave: Contrafactuais; experimentos mentais; história contrafactual.

\title{
Notes
}

${ }^{1}$ Some authors like to draw a distinction between counterfactual history and alternative history. The idea is to say that plausible analyses of 'what would have happened had $\mathrm{x}$ not occurred' are essentially different from some rather 'fantastic' narratives or allohistory. For the sake of simplicity I will not make such distinction, instead, I argue that they are essentially the same, except that the latter requires a much larger departure from actuality.

${ }^{2}$ Let $A$ be the proposition that event $a$ occurs.

${ }^{3}$ According to Lewis, this is a different way of understanding causation, not as regular successions, but a special type of dependence, a relation between two events particulars ( $c$ and $e$ ) in which the occurrence of $e$ depends on the previous (or simultaneous) occurrence of $c$. And the non-occurrence of $c$ would be followed by the non-occurrence of $e$.

${ }^{4}$ Counterfactuals are usually cashed out in terms of possible worlds. When we try to assess the truth of a counterfactual (if ... then ...) what we actually do is to use our knowledge about how the world works and then try to decide what would have been the probable outcome had any antecedent been different. As more than one outcome is possible we consider each of this possibilities as a possible world (a real entity for Lewis), and proceed to comparative similarity in order to decide which ones requires a large departure from the actual world, and which ones do not. Possible worlds are a way - and possibly the only one - of justifying the attribution of truth conditions to counterfactuals. In terms of possible worlds,

Principia 18(1): 87-113 (2014). 
we may say that in a scenario described as having extreme levels of contingency, all those possible worlds in which an alteration to $c_{1}$ is introduced and this is followed by a different type of event $E$ are closer to the actual world than any other world in which we alter $c_{1}$ while $E$ remains unaltered (this would require a larger departure from reality). In scenarios of extreme levels of necessity the opposite occurs: all possible worlds in which an alteration to $c_{1}$ is introduced and this is followed by the same type of event $E$ are closer to the actual world than any other world in which we alter $c_{1}$ and this is followed by a different type of event $E$.

${ }^{5}$ The skepticism is a consequence of two problems regarding the use of historical counterfactuals: (1) we cannot really assess the truth of these counterfactuals, even if evidence is available; (2) what is the legitimacy of introducing an alteration while holding all other conditions fixed? With respects to (2) Jon Elster suggested in 'Counterfactuals and the New Economic History' (1978) that some counterfactuals scenarios using this ceteris paribus condition seem to be illegitimate. For instance, a world in which the Nazi Germany considers the Jews the superior race is inconsistent with many historical antecedents present in Germany during the 30's. Lewis has a pragmatic response to that - a world in which the Nazi Germany considers the Jews a superior race - while all the other antecedents remain the same - would require a very large departure from reality; a world so distant that it would be fruitless to compare it with others, as we lose grip on it. In other words, we can say that far-fetched possible worlds are not plausible, and therefore not meaningful.

${ }^{6}$ The Treaty of Waitangi was signed by British representatives and Maori chiefs on 6 February 1840. Basically, the treaty established British sovereignty over New Zealand, while offering Maori protection and the right to land ownership.

7 [My translation].

${ }^{8}$ See also Tremewan, P. (ed.) (1990).

${ }^{9}$ Captain William Hobson was the British representative who had the task to get the treaty signed. After his success he became New Zealand's first Governor.

${ }^{10}$ Explaining actions requires, in some situations, to understand the thought of the historical players. Historians must "envisage" the situation in which that player stood and think out for himself what his thoughts were in that situation - this process is to be called reenactment.

${ }^{11}$ How it actually/plausibly would be, and not what the 'player' believed it would be like.

${ }^{12}$ In a sense that every historical happening/event is 'necessary'.

13 See Carr, E. H. (1962).

${ }^{14}$ Ibid.

15 This is not a counterfactual analysis of causation. However, Lewis' theory holds in both cases, had $c$ not occurred, $e$ would not have occurred, independently of the understanding of $e$ as relatively more necessary or more contingent.

${ }^{16}$ In a very personal understanding of this term, as Ferguson calls 'deterministic' scientific models of explanation, Marxism, Hegelianism and even some narrative choices.

${ }^{17}$ Again, it depends on how 'determinism' is to be defined.

${ }^{18}$ A chaotic approach to history. See Ferguson (1999).

19 This is an adapted and simplified version of John Earman's argument in "Laplacian Determinism" (1971), p.739-740.

${ }^{20}$ This has been the subject matter of some metaphysical approaches to the philosophy of history.

Principia 18(1): 87-113 (2014). 
${ }^{21}$ On this point I agree with David Lewis' (2003a) notion of causal explanation, as these are: (1) chunks of information about the causal history of an event, or (2) the act of providing such information. The satisfactoriness of a causal explanation will then depend on multiple elements, such as (a) the truth/falsity or relative verisimilitude, (b) the amount and the quality of the information, (c) how justified it is from standpoint of explainer, (d) how well it deals with our previous knowledge, (e) how clear and unambiguous the information is presented.

${ }^{22}$ Think of cases of overdetermination, for instance.

${ }^{23}$ In a charitable use of the word.

${ }^{24}$ It apparently conflicts with universal (Laplacian) determinism - a view that has already been abandoned.

Principia 18(1): 87-113 (2014). 